\title{
Enhancing Light Absorption and Prolonging Charge Separation in Carbon Quantum Dots via Cl-doping for Visible-Light-Driven Photocharge-Transfer Reactions
}

G. Murali, ${ }^{a}$ Jeevan Kumar Reddy Modigunta, ${ }^{a}$ Seongmin Park, ${ }^{a}$ Seongeun Lee, ${ }^{a}$ Hwiyoung Lee, ${ }^{a}$ Jiwon Yeon, ${ }^{a}$ Hyejin Kim, ${ }^{a}$ Young Ho Park, ${ }^{a}$ Sung Young Park, ${ }^{b}$ James R. Durrant, ${ }^{c}$ Hyojung Cha, ${ }^{c, d,{ }^{*}}$ Tae Kyu An, ${ }^{a,}{ }^{*}$ and Insik In ${ }^{a,{ }^{*}}$

a Department of Polymer Science and Engineering, Department of IT-Energy Convergence (BK21 FOUR), Chemical Industry Institute, Korea National University of Transportation, Chungju 27469, Republic of Korea.

${ }^{\mathrm{b}}$ Department of Chemical and Biological Engineering, Korea National University of Transportation, Chungju 380-702, Republic of Korea.

${ }^{\mathrm{c}}$ Department of Chemistry and Centre for Processable Electronics, Imperial College London, London W12 0BZ, United Kingdom.

d Department of Hydrogen \& Renewable Energy, Kyungpook National University, Daegu, 41566, Republic of Korea.

Corresponding authors: Hyojung Cha (hcha@knu.ac.kr), Tae Kyu An (taekyu1985@ut.ac.kr), Insik In(in1@ut.ac.kr). 
Table S1. Summary of the mass yields of the as-prepared CQDs resulting from microwave pyrolysis.

\begin{tabular}{|c|c|c|}
\hline Microwave operating time (min) & \multicolumn{2}{|c|}{ Mass Yield (wt.\%) } \\
\cline { 2 - 3 } & $\underline{\text { O-CQDs }}$ & $\underline{\text { Cl-CQDs }}$ \\
\hline $\mathbf{4}$ & 4.1 & 1.1 \\
\hline $\mathbf{6}$ & 5.5 & 5.6 \\
\hline $\mathbf{8}$ & 12.8 & 5.5 \\
\hline $\mathbf{1 0}$ & 16.9 & 3.5 \\
\hline $\mathbf{1 2}$ & & \\
\hline & 25.7 & 3.7 \\
\hline
\end{tabular}



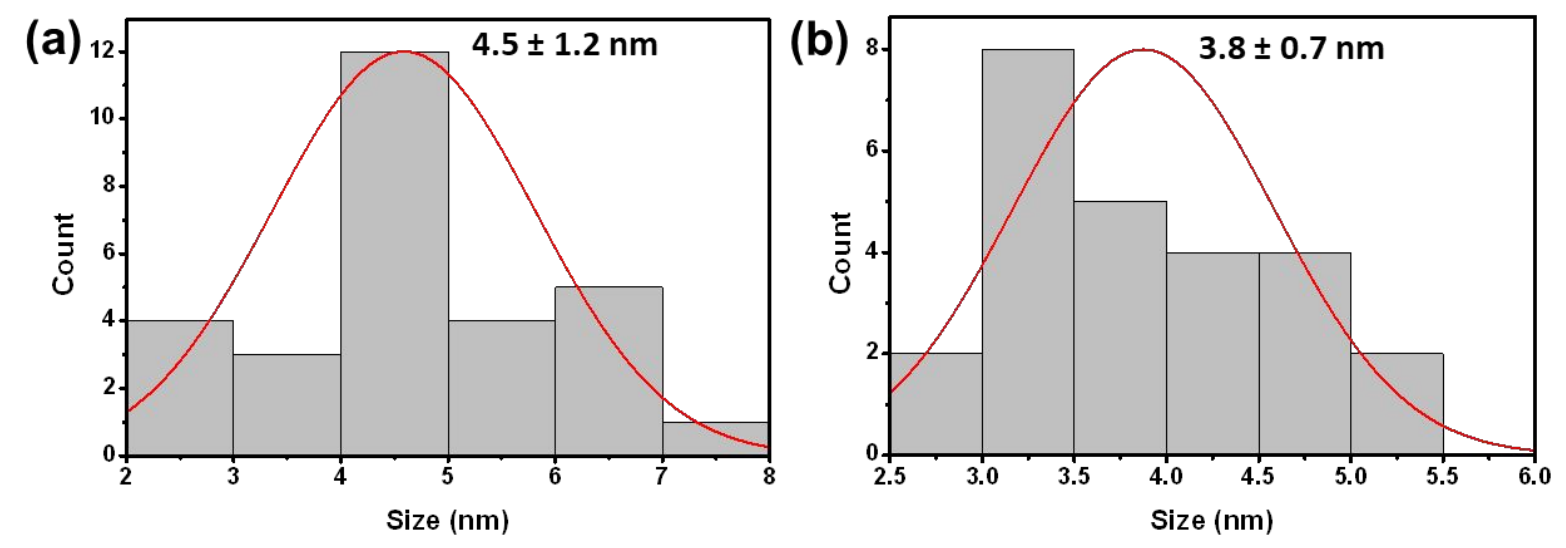

Figure S1. Size distribution histograms of (a) O-CQDs and (b) Cl-CQDs. 

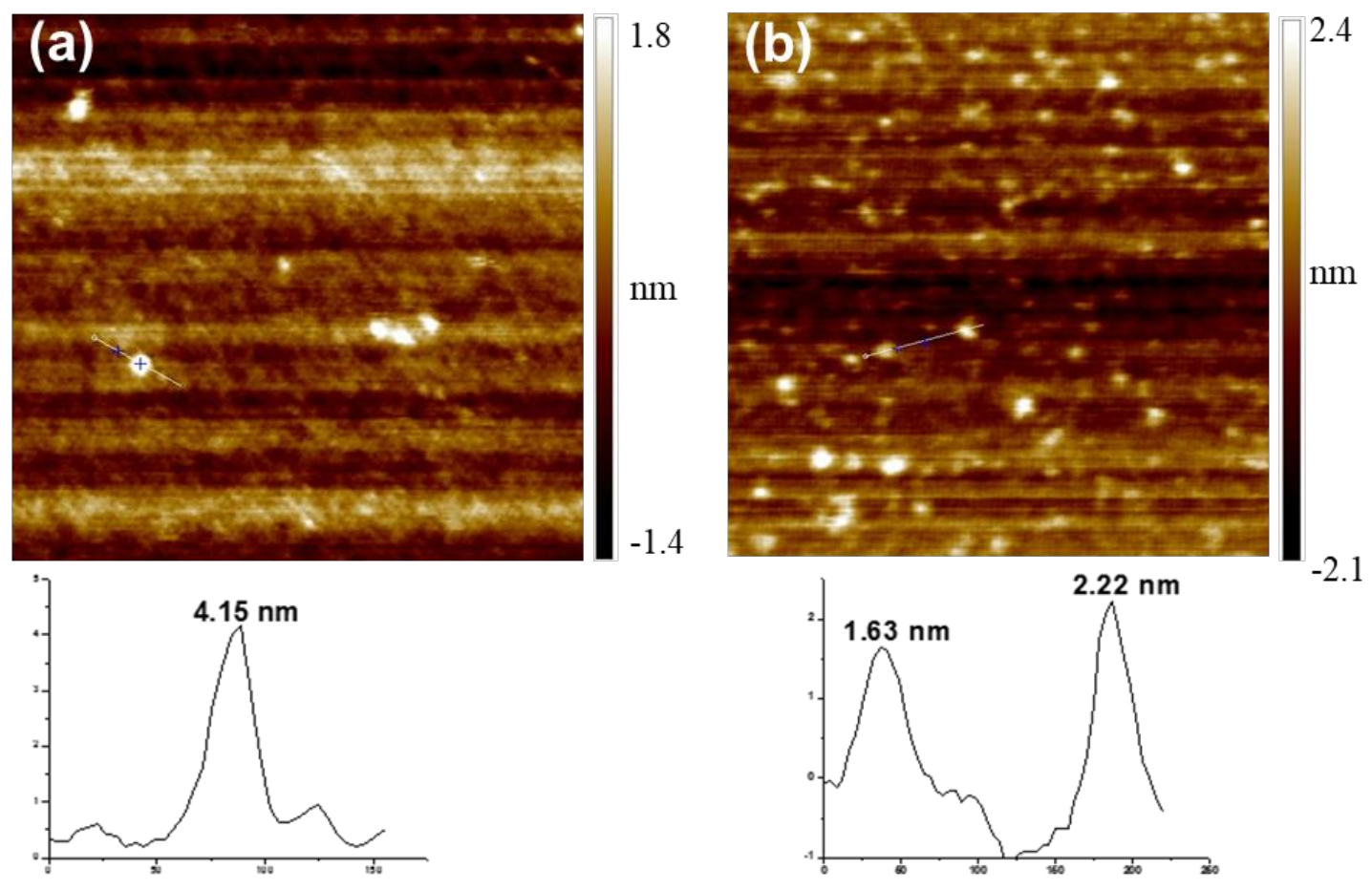

Figure S2. AFM images and height profiles along the lines shown in the AFM images for (a) the O-CQDs and (b) Cl-CQDs. 


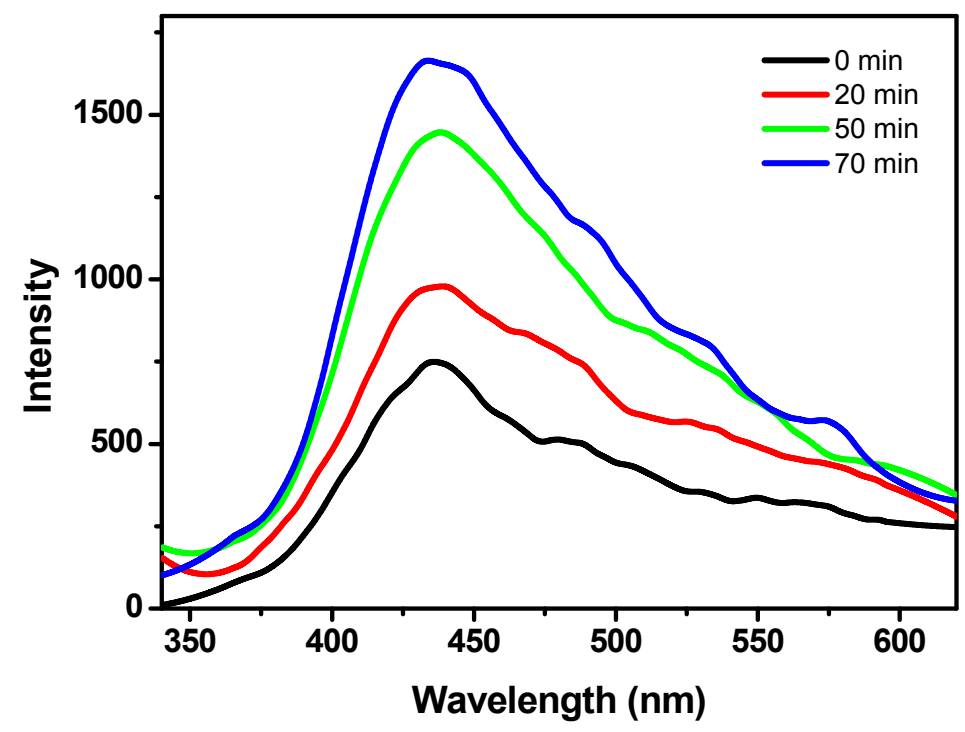

Figure S3. Fluorescence spectra of a TAOH solution generated by the mixture of Cl-CQDs and TA under the visible light irradiation.

To confirm the participation of $\mathrm{OH}$ radicals in the $\mathrm{MB}$ dye degradation activity of Cl-CQDs under the irradiation of visible light, previously reported terephthalic acid (TA)-assisted photoluminescence probing technique was employed (the concentration of Cl-CQDs maintained as $1 \mathrm{mg} \mathrm{mL}^{-1}$ ) [S1]. The reaction of TA with $\mathrm{OH}$ radicals produces 2-hydroxyterephthalic acid $(\mathrm{TAOH})$ that exhibits a fluorescence emission peak at $435 \mathrm{~nm}$ under the excitation wavelength of $315 \mathrm{~nm}$ [S1]. As shown in Figure S3, the intensity of fluorescence emission corresponding to TAOH increased with increasing the time of visible light irradiation on the mixture of TA and ClCQDs, which confirms the $\mathrm{H}_{2} \mathrm{O}$ conversion to $\mathrm{OH}$ over Cl-CQDs under the visible light irradiation. 

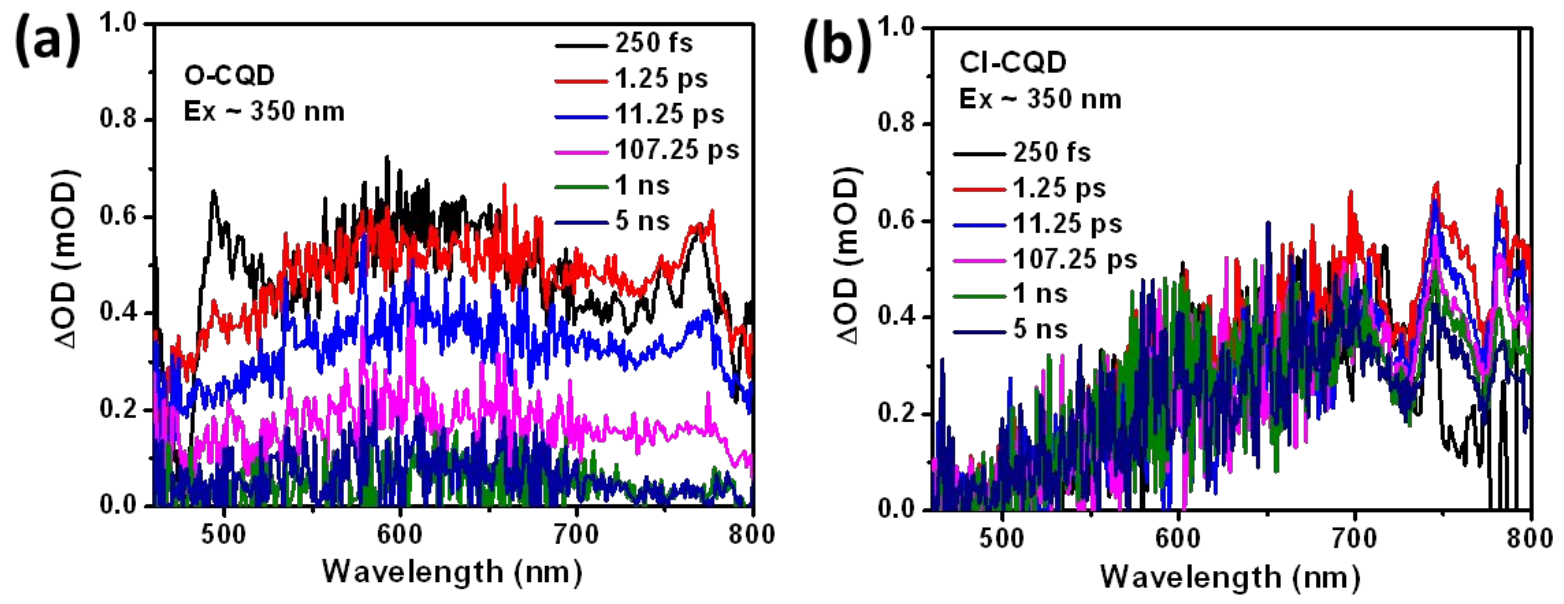

Figure S4. Transient absorption spectra of (a) the prepared O-CQD and (b) Cl-CQD films at the indicated delay times. 

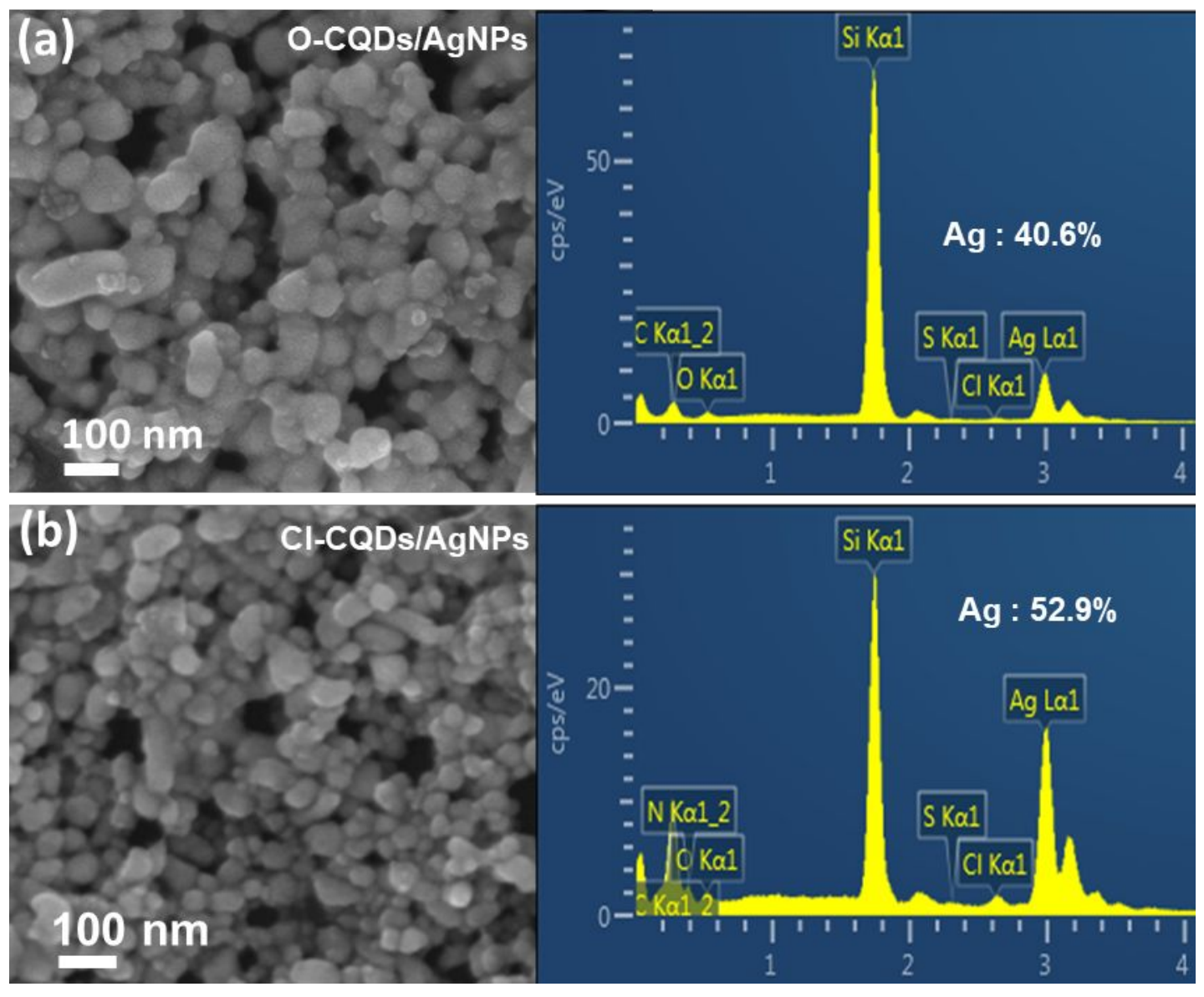

Figure S5. SEM images and corresponding EDX spectra of Ag nanoparticles produced from photocatalytic reduction of $\mathrm{AgNO}_{3}$ under visible light illumination with using the prepared (a) OCQDs and (b) Cl-CQDs. 


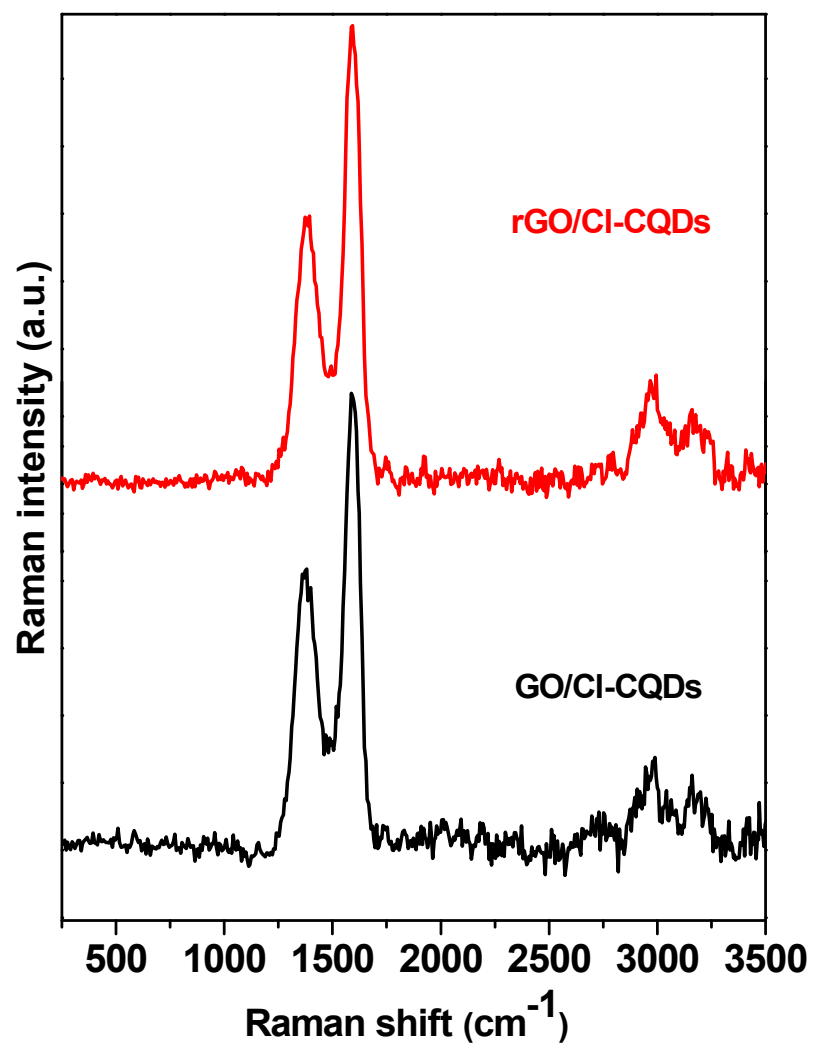

Figure S6. Raman spectra of GO/Cl-CQDs and rGO/Cl-CQDs hybrids. 


\section{References:}

[S1]. Tian, N.; Huang, H.; He, Y.; Guo, Y.; Zhang, T.; Zhang, Y. Mediator-free direct Z-scheme photocatalytic system: $\mathrm{BiVO}_{4} / \mathrm{g}-\mathrm{C}_{3} \mathrm{~N}_{4}$ organic-inorganic hybrid photocatalyst with highly efficient visible-light-induced photocatalytic activity. Dalton Trans. 2015, 44 (9), 4297-4307. 